\title{
Sex-ratio, early sex steroid profiles and cyp19a1b, dmrt1 and foxl2 gene expressions upon high temperature treatment of undifferentiated African catfish juveniles (Clarias gariepinus)
}

\author{
Saïdou Santi ${ }^{\mathrm{a}, \mathrm{b}, *}$, Vincent Gennotte ${ }^{\mathrm{a}}$, Marc Muller ${ }^{\mathrm{c}}$, Charles Melard ${ }^{\mathrm{a}}$, Aboubacar Toguyeni ${ }^{\mathrm{b}}$, \\ Syaghalirwa N.M. Mandiki ${ }^{\mathrm{d}}$, Carole Rougeot ${ }^{\mathrm{a}}$ \\ ${ }^{a}$ Aquaculture Research and Education Center (CEFRA), Liège University. 10 Chemin de la Justice, B-4500 Tihange, Belgium \\ ${ }^{\mathbf{b}}$ Aquaculture and Aquatic Biodiversity Research Unit/Natural Resources and Environmental Sciences Research and Studies Laboratory (UR-ABAQ/LERNSE), Institute of \\ Rural Development (IDR), Nazi Boni University, BP 1091, Bobo-Dioulasso, Burkina Faso \\ ${ }^{\mathrm{c}}$ Laboratory for Organogenesis and Regeneration (LOR), GIGA-Research, Liège University, Avenue de l'Hôpital, B-4000 Liège, Belgium \\ ${ }^{\mathrm{d}}$ Research Unit of Environmental and Evolutionary Biology (URBE), Institute of Life, Earth and Environment (ILEE), Namur University, Rue de Bruxelles 61, B-5000 \\ Namur, Belgium
}

\section{A R T I C L E I N F O}

\section{Key-words:}

African catfish

High temperature

Masculinization

Sex steroid hormone

Sex-determining gene

\begin{abstract}
A B S T R A C T
Different mechanisms are involved in high temperature-induced masculinization among teleost fishes. These mechanisms need to be investigated in African catfish, a species with a XX/XY genetic sex determinism that can be overridden by high temperature (HT). The influence of HT on the three main sex steroid hormones (testosterone - T, 17ß-estradiol - E2, and 11-ketotestosterone - 11KT) was assessed from non-fertilized eggs to 14 days post-hatching (dph) in eggs or whole body of six full-sib progenies reared at $28{ }^{\circ} \mathrm{C}$ (control) and $36{ }^{\circ} \mathrm{C}$ for 6 to 8 dph (high masculinizing temperature). HT effect on foxl2, cyp19a1b and dmrt1 expression was also investigated in the head at the end of the thermal treatment $(8 \mathrm{dph})$ and shortly after $(14 \mathrm{dph})$ in the six progenies. Masculinization rates in fish exposed to HT ranged from 30 to $100 \%$, but did not influence sex steroid levels. However, the masculinization rate was correlated with $11 \mathrm{KT}$ levels at 1 -h post-fertilization, suggesting that $11 \mathrm{KT}$ level at this phase may influence the masculinization potential. Expression of foxl2 was not detected in the head during the experimental period while, to our knowledge, this is the first report of $d m r t 1$ expression in teleost fish head (perhaps in brain). Similar to sex steroid hormones, HT did not induce significant changes in cyp19a1b or $d m r t 1$ relative expressions in the brain. Nevertheless, when results were split into two groups, according to the masculinization rates of progenies, lower thermosensitive progenies showed high cyp19a1b relative expression shortly after HT treatment, while in control groups, highly thermosensitive progenies displayed high dmrt1 relative expression at $14 \mathrm{dph}$. While this may be true, a direct link between the HT treatment and the biological indicators analyzed was not clear and the mechanisms of masculinization have to be further investigated, particularly in the gonad.
\end{abstract}

\section{Introduction}

African catfish, Clarias gariepinus, is a species with a $\mathrm{XX} / \mathrm{XY}$ genetic sex determination system (Galbusera et al., 2000) influenced by temperature (Santi et al., 2016). Although a large body of literature focused on the mechanisms through which temperature affects sex differentiation in fish, like the Nile tilapia (which share the same biotope with African catfish) (Baroiller and D'Cotta, 2016; Baroiller et al., 2009; Baroiller et al., 1999; Shen and Wang, 2014), no data exists concerning
African catfish, to our knowledge.

The classical view of sex development in fish supposed that sexdetermining genes (major factor) act as upstream genes controlling downstream genes, that are referred as sex-differentiating genes, and which in turn control sex steroid hormone production to promote the appropriate sexual phenotype. The new concept suggests that sex is not defined through a single genetic cascade or hierarchical cascade within a genetic network, but through a continuum in which genetic, parental, environmental and random factors act together in a non-hierarchical

\footnotetext{
* Corresponding author at: Aquaculture and Aquatic Biodiversity Research Unit/Natural Resources and Environmental Sciences Research and Studies Laboratory (UR-ABAQ/LERNSE), Institute of Rural Development (IDR), Nazi Boni University, BP 1091, Bobo-Dioulasso, Burkina Faso

E-mail address: saidou.santi@gmail.com (S. Santi).
} 
network to influence cell proliferation and hormone levels and consequently induce the appropriate sexual phenotype (Baroiller and D'Cotta, 2016; Heule et al., 2014; Mei and Gui, 2015; Perrin, 2016). Temperature acts on sex steroid hormone levels through the regulation of sexlinked gene expression or on germ cell proliferation through epigenetic or genetic processes (Baroiller and D'Cotta, 2016; Piferrer, 2013; Selim et al., 2009; Uchida et al., 2004).

The $17 \beta$-estradiol (E2) is main sex steroid influencing sex differentiation in fish. Its upregulation and downregulation induced respectively female and male differentiation (Diotel et al., 2010; Tokarz et al., 2015). E2 synthesis from testosterone or androstenedione is catalyzed by the cytochrome $\mathrm{P} 450$ aromatase, the transcription product of cyp19a1 gene (D'Cotta et al., 2001b; Guiguen et al., 2010). In fish, two isoforms of aromatase encoded by two different genes with different expression patterns were reported: the gonadal aromatase gene (cyp19a1a) and the brain aromatase gene (cyp19a1b) (Diotel et al., 2010; Kwon et al., 2001; Tchoudakova and Callard, 1998). The ovarian differentiation pathway is triggered and maintained by upregulation of gonadal aromatase, whereas cyp19a1a is downregulated in testicular differentiation (Guiguen et al., 2010; Piferrer et al., 2012). The repression of aromatase gene expression by HT is suggested to contribute to masculinization in thermosensitive species (Baroiller et al., 2009; Guiguen et al., 2010; Piferrer et al., 2012). Indeed, D'Cotta et al. (2001b) showed (in Nile tilapia) that aromatase gene expression was repressed during HT treatment; in both genetic male and masculinized female gonads. These authors suggested that aromatase gene repression is required in gonads (and perhaps in the brain) to drive sex differentiation towards testis development. Foxl2 (forkhead box protein L2), which activates aromatase transcription, was inhibited by HT in both Nile tilapia and Japanese flounder (Paralichthys olivaceus) (Baroiller et al., 2009), consistent with the decreased cyp19a1a gene expression.

Nonetheless, HT-induced masculinization is not only the result of female pathway repression, but can result from upregulation of the male differentiation pathway. In Nile tilapia, HT first induced an increase of $d m r t 1$ (doublesex and Mab-3 (DM) related transcription factor 1) and amh (Anti-müllerian hormone) gene expressions in gonads of temperature-masculinized females (XX), followed by repression of foxl2 and cyp19a1a gene expressions, thus overriding the chromosomic female sex (Poonlaphdecha et al., 2013). In this species, HT also induced an upregulation of other testicular differentiating genes such as sox9a, sox $9 b$, dax 1 and cyp $11 b$ (involved in 11-ketotestosterone - 11KT biosynthesis) (Baroiller and D'Cotta, 2016). Similarly, a raise in 11KT level induced by HT was observed in pejerrey (Odontesthes hatcheri) (Hattori et al., 2009). In medaka, HT treatment during embryonic stages induced a high expression of the dmrt1 gene in genetic females, suggesting that HT accelerates the molecular pathway leading to testicular differentiation (Hattori et al., 2007).

In teleosts, aromatase expression is high in the brain compared to mammals, resulting in high production of neuroestrogens (Blazquez and Somoza, 2010; Le Page et al., 2010). The brains aromatase cyp19a1b gene is specifically regulated there, suggesting early sexualization of the brain (Gennotte et al., 2017; Senthilkumaran et al., 2015). Its expression is more elevated in HT-induced male pejerrey (Diotel et al., 2010). Likewise, in rainbow trout (Oncorhynchus mykiss), brain aromatase gene expression and its enzyme activity were higher in male brain before testicular morphological differentiation (VizzianoCantonnet et al., 2011). These findings suggest that brain aromatase and neuroestrogens might be implicated in male brain differentiation.

The thermosensitive period for sex differentiation in African catfish occurs very early, from hatching to 23 days post-hatching (dph). Equally important, the highly thermosensitive period is short and extends from 6 to $8 \mathrm{dph}$, long before the appearance of the first histological signs of sex differentiation at $25 \mathrm{dph}$. When applied during this period, high temperature frequently masculinized progenies up to 80-100\% (Santi et al., 2017, 2016). We focused the present study on the period before ( $0 \mathrm{hpf}$ ) until shortly after (14 dpf) the highly thermosensitive period, because in African catfish, some progenies were not thermosensitive after $14 \mathrm{dph}$ (Santi et al., 2016). Considering that sex steroid hormones are involved in sex differentiation process and that steroidogenesis occurs during the early life stages in teleosts, we first aimed to determine the effect of HT on sex steroid hormone levels in whole body African catfish. Based on the previous reports on early expression of brain aromatase in several fish species (Devlin and Nagahama, 2002; Diotel et al., 2010; Le Page et al., 2010), we further focused on the effect of HT on cyp19a1b gene expression in heads, as well as some additional putative sex-differentiating genes (dmrt1, and foxl2), during and shortly after the highly thermosensitive period.

\section{Materials and methods}

The experiments were carried out according to the European animal welfare recommendations and to the guidelines of the University of Liège Ethical Committee (CEFRA, LA 1610488).

\subsection{Fish and rearing conditions}

Six full-sib progenies were obtained by artificial reproduction of domesticated African catfish breeders following the method previously described (Santi et al., 2016). Two-day post-hatching (dph) larvae were transferred into 50-1 tanks at an initial stocking density of 20 larvae $1^{-1}$. Tanks were supplied with water from a recirculating system at $28.0^{\circ} \mathrm{C}$ and exposed to a $12 \mathrm{~L}: 12 \mathrm{D}$ photoperiod. Fish rearing conditions were the same as described by Santi et al. (2016).

Each progeny was split into 4 batches, 2 duplicates in the treated group and 2 duplicates in the control group. In control groups, fish were reared at $28.0 \pm 1.0^{\circ} \mathrm{C}$ from 2 to $70 \mathrm{dph}$ (until sex-ratio analysis). The treatment consisted of the application of high rearing temperature $\left(36.0 \pm 0.2^{\circ} \mathrm{C}\right.$ ) from 6 to $8 \mathrm{dph}$ (Santi et al., 2016). The experimental temperature was maintained in each tank with an individual heating system (Biotherm 2000 thermostat connected to two 300-W heaters). At $6 \mathrm{dph}$, the experimental temperature $\left(36^{\circ} \mathrm{C}\right)$ was reached within $3 \mathrm{~h}$ for a 3-day treatment. At the end of the treatment, water was cooled down to $28^{\circ} \mathrm{C}$ within $3 \mathrm{~h}$. Before and after the thermal treatment, fish were reared at $28^{\circ} \mathrm{C}$ until sex-ratio analysis at $70 \mathrm{dph}$.

\subsection{Sex-ratio analysis}

At 70 dph, 100 fish (mean body weight: $48.11 \pm 20.42 \mathrm{~g}$ ) per batch were randomly sampled and euthanized with an overdose $\left(200 \mathrm{mg} \mathrm{l}^{-1}\right)$ of benzocaïne (Sigma-Aldrich). Phenotypic sex was determined using the aceto-carmine squash method for sexing juvenile fish described by Guerrero and Shelton (1974). Sex was identified according the presence of oocytes in female gonads and on the lobular morphology of testis for males.

\subsection{Sex steroid hormones assay}

\subsubsection{Egg, larva and juvenile sampling}

Sex steroid hormone (testosterone - T, 17 $\beta$-estradiol - E2, and 11ketotestosterone - $11 \mathrm{KT}$ ) concentrations were assessed during the thermosensitive period of sex differentiation, from non-fertilized eggs (maternal transmission) to $14 \mathrm{dph}$. One gram of eggs was sampled after spawning and at one-hour post-fertilization (hpf). Thereafter, one gram of larvae or juveniles was sampled in duplicate at 2, 4, 6, 7, 8, 10 and 14 $\mathrm{dph}$. At each sampling time, $\pm 0.5 \mathrm{~g}$ of eggs were counted and 60 fish were weighed $( \pm 0.01 \mathrm{mg}$ ) to determine the number of eggs and fish per sample (Table 1). All samples were stored at $-80^{\circ} \mathrm{C}$ before sex steroid extraction. Sampling dates were divided in three periods according to HT treatment: before ( 2 to $6 \mathrm{dph}$ ); during (7 to $8 \mathrm{dph}$ ) and after (10 to $14 \mathrm{dph}$ ). 
Table 1

Number and weight (mean of 6 progenies \pm SE) of eggs, larvae and juveniles Clarias gariepinus sampled at different ages for sex steroid hormones assay.

\begin{tabular}{|c|c|c|c|c|c|c|}
\hline \multirow[t]{2}{*}{ Age } & \multicolumn{3}{|l|}{ Control } & \multicolumn{3}{|c|}{ High temperature treated } \\
\hline & Total used eggs/fish & MW (mg) & Extract quantities (g) & Total used fish & MW (mg) & Extract quantities (g) \\
\hline NFE & 3785 & $1.59 \pm 0.10$ & $1.005 \pm 0.003$ & & & \\
\hline $1 \mathrm{HPF}$ & 2523 & $2.39 \pm 0.15$ & $1.009 \pm 0.013$ & & & \\
\hline $2 \mathrm{DPH}$ & 1792 & $3.62 \pm 1.24$ & $1.006 \pm 0.003$ & & & \\
\hline $4 \mathrm{DPH}$ & 1190 & $5.75 \pm 2.10$ & $1.007 \pm 0.002$ & & & \\
\hline $6 \mathrm{DPH}$ & 1020 & $6.34 \pm 1.93$ & $0929 \pm 0.104$ & & & \\
\hline $7 \mathrm{DPH}$ & 887 & $7.88 \pm 3.30$ & $0.975 \pm 0.066$ & 900 & $6.28 \pm 2.13$ & $0.949 \pm 0.082$ \\
\hline $8 \mathrm{DPH}$ & 725 & $8.78 \pm 1.97$ & $0.949 \pm 0.131$ & 846 & $7.68 \pm 2.05$ & $0.940 \pm 0.142$ \\
\hline $10 \mathrm{DPH}$ & 575 & $12.18 \pm 4.58$ & $1.009 \pm 0.010$ & 730 & $9.65 \pm 3.57$ & $0.966 \pm 0.116$ \\
\hline $14 \mathrm{DPH}$ & 359 & $21.33 \pm 10.65$ & $1.008 \pm 0.005$ & 427 & $17.29 \pm 7,15$ & $0.981 \pm 0.047$ \\
\hline
\end{tabular}

MW: mean weight; NFE: non-fertilized eggs; HPF: hour post-hatching; DPH: day post-hatching.

Table 2

List of primers used for RT-PCR and the Genbank accession number of cDNA sequences for Clarias gariepinus and Clarias batrachus.

\begin{tabular}{|c|c|c|c|}
\hline Gene & Genbank Reference & Forward primer ( $5^{\prime}$ to $3^{\prime}$ direction) & Reverse primer ( $5^{\prime}$ to $3^{\prime}$ direction) \\
\hline Cyp19a1b & GU220076.1 & ACTGGATGAACCGGACTTTG & GCACCAGCATGAAGAACAGA \\
\hline Foxl2 & HQ680981.1 & GAAGCCGCCGTACTCTTATG & CCAGTAGTTCCCCTTCCTCTC \\
\hline Dmrt1 & AF439561.1 & TGCACACCAGTGAACCTCTC & GTATGCTGGATAGCGGGAAG \\
\hline Ef1 $\alpha$ & AB916539.1 & CTCTCAGGGCTATGCTCCAG & TTCAGGTTCTTGGGGTTGTC \\
\hline$\beta$-actin & JN806115.1 & ACCGAAGTCCATCACAATACCAGT & GAGCTGCGTGTTGCCCCTGAG \\
\hline Gapdh & AF323693.1 & CTAAGCGCGTGGTAGTCTCC & GGGAGCCAAGCAGTTAGTTG \\
\hline
\end{tabular}

\subsubsection{Sex steroid hormone extraction and assays}

Sex steroid hormones were extracted from whole eggs or bodies, using the alcohol-dichloromethane method from Rougeot et al. (2007), adapted from D'Cotta et al. (2001a). The extraction efficiency was $86 \%$ for $\mathrm{T}$ and $11 \mathrm{KT}$, and $81 \%$ for E2. After extraction, T, E2 and $11 \mathrm{KT}$ concentrations were assayed in these extract samples by radioimmunoassay (RIA) following the method of Fostier and Jalabert (1986) adapted by Mandiki et al. (2005). One set of assays was done for each hormone and the intra-assay coefficients of variation were $7.72 \%$, $7.20 \%$ and $9.35 \%$ respectively for T, E2 and $11 \mathrm{KT}$. The detection limits of the assays ranged from 8.56 to $9.93 \mathrm{pg} \mathrm{ml}^{-1}$ for the three steroids.

\subsection{Gene expression analysis}

\subsubsection{Juvenile sampling}

For gene expression analysis, fish were sampled in duplicate at 6,8 and $14 \mathrm{dph}$ in control and HT groups. At each sampling date, 30 fish were sampled in each replicated group (control and HT), kept in RNA Later (Thermo Fisher Scientific ${ }^{\circledast}$ ) and stored at $-20^{\circ} \mathrm{C}$ until total RNA extraction.

\subsubsection{Total RNA extraction and reverse transcription}

RNA was extracted from heads and dissections were performed in RNA Later. Each sample was then divided into two replicates (15 heads each) and total RNA was extracted from each 15-pooled heads. RNeasy ${ }^{\circledR}$ Plus Universal Mini Kit of QIAGEN was used for total RNA extraction following the kit protocol. Extracted total RNA was then suspended in $80 \mu \mathrm{l}$ of RNase-free water, quantified with NanoDrop and stored at $-80^{\circ} \mathrm{C}$.

Reverse transcription (RT-PCR) was performed using the iScriptTM cDNA Synthesis Kit from BIO-RAD. One $\mu$ g of each total RNA sample

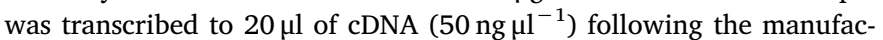
turer's protocol. cDNA samples were 2 -fold diluted, with DNase- and RNase-free water, to obtain a final concentration of $25 \mathrm{ng} \mathrm{\mu l}^{-1}$ and used for gene expression quantification by real-time PCR. Negative control on reverse transcription (without reverse transcriptase: - RT-) was performed for each sample.
2.4.3. Relative quantification of cyp19a1b, foxl2, and dmrt1 expression levels

Doublesex- and Mab-3-related transcription factor-1 (dmrt1), brain aromatase (cyp19a1b) and fork head transcription factor (foxl2) expression analysis was performed on an ABI Prism ${ }^{\circledR} 7900$ HT Fast RealTime PCR System (Applied Biosystems, Foster, CA, USA). Expression levels of these genes were assessed relatively to a reference gene (elongation factor 1-alpha -ef1 $\alpha$ ) and to control samples ( $6 \mathrm{dph}$ ). Three genes, including $\beta$-actin and glyceraldehyde-3-phosphate dehydrogenase - gapdh from C. gariepinus and ef1 $\alpha$ from $C$. batrachus, were tested as reference genes. Only ef $1 \alpha$ was used as reference gene due to its relative constant expression within our samples. $E f 1 \alpha$ primers were designed from $C$. batrachus, a species close to $C$. gariepinus, because this gene sequence was unknown in $C$. gariepinus. qPCR primers were designed for each gene cDNA sequence (Table 2).

For qPCR, samples (cDNA and RT-) were amplified in triplicate within a total reaction volume of $15 \mu$ l containing $7.5 \mu$ l of MasterMix ( $2 \times$ TakyonTM RoxSYBR $^{\circledR}$ MasterMix dTTP Blue, Eurogentec), $4.5 \mu \mathrm{l}$ of primers $(300 \mathrm{nM}), 2 \mu \mathrm{l}$ of cDNA ( $50 \mathrm{ng}$ ) and $1 \mu \mathrm{l}$ of RNase- and DNasefree water. PCR conditions were as follows: $50{ }^{\circ} \mathrm{C}$ for $2 \mathrm{~min}$ (carry over prevention); $95.0^{\circ} \mathrm{C}$ for $10 \mathrm{~min}$ (enzyme activation); 40 cycles of $95.0^{\circ} \mathrm{C}$ for $15 \mathrm{~s}$ (denaturation) and $60.0^{\circ} \mathrm{C}$ for $30 \mathrm{~s}$ (annealing / extension); and a dissociation at $95.0^{\circ} \mathrm{C}$ for $15 \mathrm{~s}, 60.0^{\circ} \mathrm{C}$ for $15 \mathrm{~s}$ and $95.0^{\circ} \mathrm{C}$ for $15 \mathrm{~s}$.

The relative expression of each target gene is presented as foldchange in target gene expression relative to the reference gene (ef1 $\alpha$ ) and to the control sample using $2^{-\Delta \Delta \mathrm{CT}}$ method (Livak and Schmittgen, 2001).

\subsection{Statistical analysis}

Sex-ratio of the progenies was analyzed using the $2 \times 2$ contingency chi-square $\left(\chi^{2}\right)$ test. For each progeny, sex-ratio of the control group was compared against a 50:50 theoretical sex-ratio. Sex-ratio of HT group was compared against its own control $\left(28^{\circ} \mathrm{C}\right)$. For sex steroid hormone concentrations and relative gene expressions $(n=6$ progenies), data normality was tested using D'Agostino \& Pearson omnibus normality test before comparing means by ANOVA and multiple comparison with Sidak test. All differences were considered significant 
Table 3

Sex ratio and masculinization rate (\%) of Clarias gariepinus juveniles (70 days post-hatching) reared at $28{ }^{\circ} \mathrm{C}$ (control) or transiently exposed to $36^{\circ} \mathrm{C}$ from 6 to $8 \mathrm{dph}$ (HT-treated).

\begin{tabular}{llll}
\hline Progeny & Control & HT-treated & \\
\cline { 2 - 4 } & $\%$ Males & \% Males & \% Masculinization \\
\hline 1 & 48.0 & $64.0^{*}$ & 30.8 \\
2 & 56.0 & $82.0^{*}$ & 59.1 \\
3 & 50.0 & $80.0^{*}$ & 60.0 \\
4 & 41.0 & $95.0^{*}$ & 91.5 \\
5 & 41.0 & $97.0^{*}$ & 94.9 \\
6 & 61.0 & $100^{*}$ & 100 \\
\hline
\end{tabular}

* Significantly different $(p<.05)$ from the control.

when $p<.05$; statistical tests and graph were performed with GraphPad Prism v. 6.00 (GraphPad Software, La Jolla California USA). The Pearson (parametric test) or Spearman (non-parametric test) correlation test was performed, whether data have respectively normal distribution or not, to determine different correlations. Correlations were considered significant when $p<.05$.

\section{Results}

\subsection{Sex-ratio analysis}

At $70 \mathrm{dph}$, the sex-ratio of control groups in all progenies was not significantly different from a theoretical 50:50 sex-ratio. Male proportion in these groups ranged from 41 to $61 \%$. All HT-treated groups displayed a significantly $(\mathrm{p}<.05)$ skewed sex-ratio towards the male phenotype when compared to their respective controls. Male proportion in HT groups ranged from 64 to $100 \%$ with masculinization rates ranging from 30 to $100 \%$ (Table 3). To analyze steroid level and gene expression results, we divided progenies into two groups (of three progenies each) depending on their thermosensitivity and hence their masculinization rates: the first group (M60) had masculinization rates ranging from 30 to $60 \%$, the second one (M100) from 91 to $100 \%$.

\subsection{Sex steroid hormone concentrations}

Concentrations of $\mathrm{E} 2$ and $\mathrm{T}$ in non-fertilized eggs revealed an important variability between progenies. The highest concentrations were observed in non-fertilized eggs for E2 and $\mathrm{T}$ (14 \pm 5 and $10 \pm 4 \mathrm{ngg}^{-1}$ respectively) and at $4 \mathrm{dph}$ for $11 \mathrm{KT}$ $\left(2.51 \pm 0.70 \mathrm{ng} \mathrm{g}^{-1}\right)$. E2 and $\mathrm{T}$ concentrations tended to decrease during the remaining experimental period (Fig. 1). Only E2 concentrations in non-fertilized and in 1 hpf eggs of control groups were significantly different $(\mathrm{p}<.05)$ from the other developmental stages. Compared to E2 and T, 11KT levels remained stable below $3 \mathrm{ng} \mathrm{g}^{-1}$ for the entire experimental period in both control and HT groups. In HT groups, there was no significant difference in all sex-steroid hormone concentrations from 7 to $14 \mathrm{dph}$. Similarly, no significant difference was observed between control and HT groups for T, E2 and $11 \mathrm{KT}$ (Fig. 1). Ratios between the concentrations of the three analyzed steroids (E2/T, E2/11KT and $11 \mathrm{KT} / \mathrm{T}$ ) were calculated (data not shown) but revealed no noteworthy trend or significant difference between control and HT groups.

\subsection{Relation between masculinization rates and sex steroid hormone levels}

To reveal possibly more subtle relations between thermal sensitivity and hormone levels, we first compared the low sensitivity M60 to the high sensitivity M100 groups at the different stages; as expected, no significant differences were observed for the three sex steroids within the control groups (Fig. 2). In contrast, the $T$ concentration was significantly higher in M60 than in M100 HT batches from 7 to $8 \mathrm{dph}$, corresponding to the HT treatment period (Fig. 2).

In a second approach, we investigated possible correlations between sex reversal rates and sex steroid levels in individual groups. In 1-hpf eggs, 11KT concentration increased significantly $\left(R^{2}=0.6542\right.$, $p=.0014$ ) with masculinization rates (Fig. 3). Correlations between masculinization rate and either $\mathrm{E} 2$ or $\mathrm{T}$ concentrations in all sampling data were calculated (data not shown) but revealed no noteworthy trend.

\subsection{Expression analysis of putative sex-differentiating genes}

Gene expression analysis was performed on mRNAs extracted from head just before ( $6 \mathrm{dph})$, immediately after ( $8 \mathrm{dph}$ ) and 6 days after (14 dph) HT treatment.

No expression of foxl2 was observed on control or HT groups. Cyp19a1b and dmrt1 relative expressions were not significantly different between control and treated groups during the entire experimental period or within these groups (Fig. 4). No significant differences were observed between control M60 and M100 groups for cyp19a1b relative expression during the entire experimental period (Fig. 5). However, the M60 group displayed a significantly higher $(\mathrm{p}<.05)$ cyp19a1b relative expression than M100 groups at $14 \mathrm{dph}$ in the HT batch. Conversely, the relative expression of dmrt1 in control M100 was significantly higher $(\mathrm{p}<.05)$ than control M60 at $14 \mathrm{dph}$, whereas no significant difference was observed in HT batches (Fig. 5).

\subsection{Relations between sex steroid hormone levels, masculinization rates and putative sex-differentiating gene expressions}

No significant correlations were found between cyp19a1b and dmrt1 relative expressions and sex steroid hormones concentrations at the end (8 dph) or shortly after (14 dph) HT treatment.

Masculinization rate was not correlated with the relative expressions of cyp19a1b and dmrt 1 at 8 and $14 \mathrm{dph}$. There was no correlation (in control groups) between the relative expressions of these genes and the proportion of male.

\section{Discussion}

African catfish displays a genetic (XX/XY) sex determining system (Galbusera et al., 2000) that can be influenced by high temperature (HT) during early life stages (Santi et al., 2016). The mechanism by which HT induces masculinization in this species needed to be explored. Therefore, we concentrated our study on the period during and shortly after the masculinization treatment and investigated, for the first time in this species, the effect of $\mathrm{HT}\left(36^{\circ} \mathrm{C}\right.$ from 6 to $\left.8 \mathrm{dph}\right)$ on the levels of the three main sex steroid hormones (testosterone $-\mathrm{T}, 17 \beta$ estradiol - E2 and 11-ketotestosterone - 11KT) and on the expression of putative sex-differentiating genes (cyp19a1b, dmrt1 and foxl2).

Although HT treatment induced a significant masculinization in all tested progenies (masculinization rates ranging from 30 to 100\%), we did not observe any differences in T, E2 or 11KT levels during the thermosensitive period; suggesting that high temperature may not act directly on sex steroid production to induce masculinization in African catfish. In the Japanese flounder, HT also did not also affect whole body T levels during gonadal differentiation (Sun et al., 2013), however, E2 levels were significantly reduced during this period (Fan et al., 2017; Sun et al., 2013). In Nile tilapia (D'Cotta et al., 2001a) and European sea bass (Socorro et al., 2007), it was suggested that 11KT concentrations were not influenced by HT treatment as the expression of cyp $11 b$, the gene coding for $11 \beta$-hydroxylase, was not influenced during HT treatment. In contrast, when pejerrey larvae were reared at a highmasculinizing temperature, a rise of $11 \mathrm{KT}$ level in the whole body (Hattori et al., 2009) and a rise of cyp $11 b$ expression in presumable Leydig cells was observed during the sex determination period 


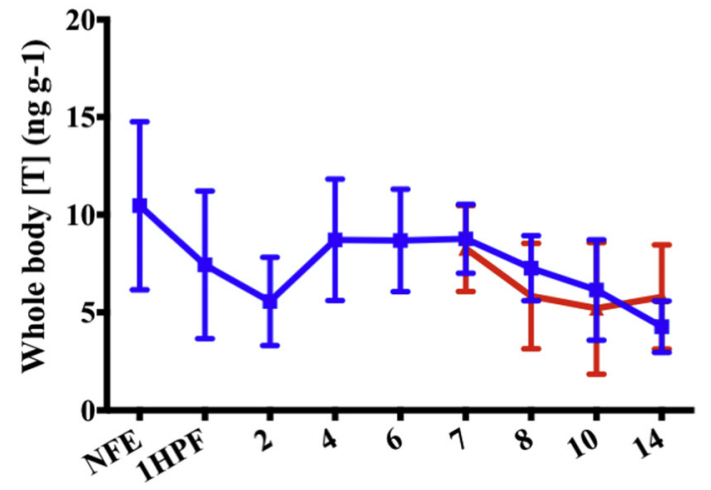

Age (days post-hatching)

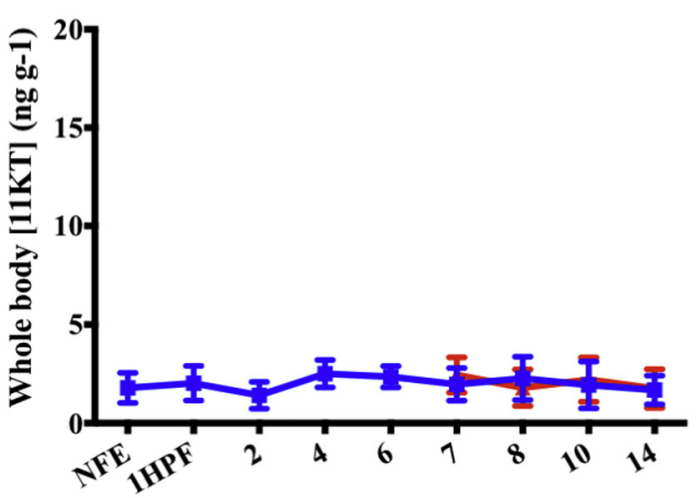

Age (days post-hatching)

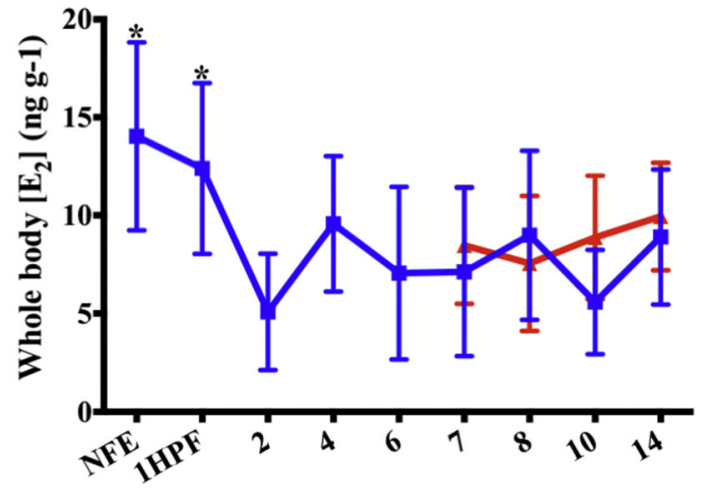

Age (days post-hatching)

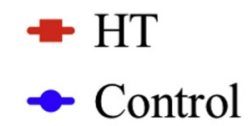

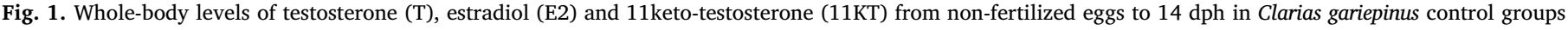

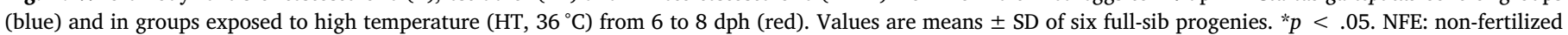
eggs; 1HPF: 1-h post fertilization. (For interpretation of the references to colour in this figure legend, the reader is referred to the web version of this article.)

\section{(Fernandino et al., 2013).}

In our study, high $\mathrm{T}$ and $\mathrm{E} 2$ levels were measured in non-fertilized eggs, suggesting an important transfer from maternal origin. These levels decreased during the subsequent developmental periods. Since steroids are involved in several processes such as embryonic development, metabolism, immune responses, osmoregulation or circadian rhythms (Tokarz et al., 2015), these "maternal" sex steroid hormones could be used in the brain and/or the gonads as precursor for both endogenous steroidogenesis and sex differentiation processes during early life (Rougeot et al., 2007). No correlation between the concentrations of maternal sex steroid hormones and the sex-ratio of the progenies was observed in Nile tilapia (Gennotte et al., 2014) and Eurasian perch (Rougeot et al., 2007). In contrast, in African catfish, our results reveal that $11 \mathrm{KT}$ levels in $1 \mathrm{hpf}$ eggs are positively correlated with the masculinization rate, even though HT did not affect its production during and after treatment. Since no significant difference was observed between $11 \mathrm{KT}$ levels in non-fertilized and $1 \mathrm{hpf}$ eggs, we assume that the $11 \mathrm{KT}$ levels in $1 \mathrm{hpf}$ larvae result from maternal transfer. This provides preliminary evidence that there is maternal contribution to thermosensitivity of sex differentiation processes in the progenies of African catfish. Howbeit, further investigations are needed on $11 \mathrm{KT}$ levels in fertilized eggs during and after HT treatment to confirm this hypothesis.

The relative expression of doublesex and Mab-3 (DM) related transcription factor 1 (dmrt1) was measured in heads during and after HT treatment. This gene is expressed in gonads during testicular differentiation in rainbow trout, Oncorhynchus mykiss (Marchand et al., 2000), African catfish (Raghuveer et al., 2011; Raghuveer and Senthilkumaran, 2009), Nile tilapia (Ijiri et al., 2008) and zebrafish (Webster et al., 2017). To our knowledge, this is the first report of dmrt1 gene expression in teleost fish head (perhaps in brain).
In Nile tilapia, dmrt1 expression was up-regulated upon HT induction in the gonads and trunks of temperature-masculinized females (XX) (Poonlaphdecha et al., 2013), while it decreased in estrogen-treated male differentiating gonads in rainbow trout (Marchand et al., 2000). In African catfish, HT did not induce a significant change in dmrt1 expression, neither during the experimental period nor between control and HT groups. Although no significant relations were found (in African catfish) between dmrt1 gene relative expression and masculinization rate, neither with sex-ratio in control group, this gene showed higher expression in M100 (high masculinized progenies) than in M60 (low masculinized progenies) control group at $14 \mathrm{dph}$; signifying that the most thermosensitive progenies displayed a higher expression of dmrt1 gene in their head (perhaps in brain) during early life stages. As dmrt1 gene expression was assessed in the brain and it is a male-promoting gene in fish, our results suggested firstly the implication of brain in African catfish sex differentiation process and secondly that $d m r t 1$ could be a candidate gene for further studies on brain sexualization in teleost fishes.

Similar to dmrt1 gene relative expression, HT did not induce significant change in either cyp19a1b gene expression or during the experimental period, nor between control and HT groups. In Nile tilapia, cyp19a1b expression did not change significantly in the brain of fish submitted to $\mathrm{HT}\left(36^{\circ} \mathrm{C}\right.$ ) from 10 to $22 \mathrm{dph}$ (Li et al., 2014), but it was down-regulated in the brain of fish submitted to HT from 10 to $19 \mathrm{dph}$. In this species, undifferentiated juveniles exhibited a sexual dimorphism of brain aromatase enzyme activity which was higher in females. HT $\left(35^{\circ} \mathrm{C}\right)$ induced a nearly three-fold decrease of brain aromatase activity in masculinized genetic females but also in genetic males (D'Cotta et al., 2001b). These authors also showed that HT treatment induced a repression of gonadal aromatase gene expression in the Nile tilapia. Conversely, in pejerrey, brain aromatase level is 

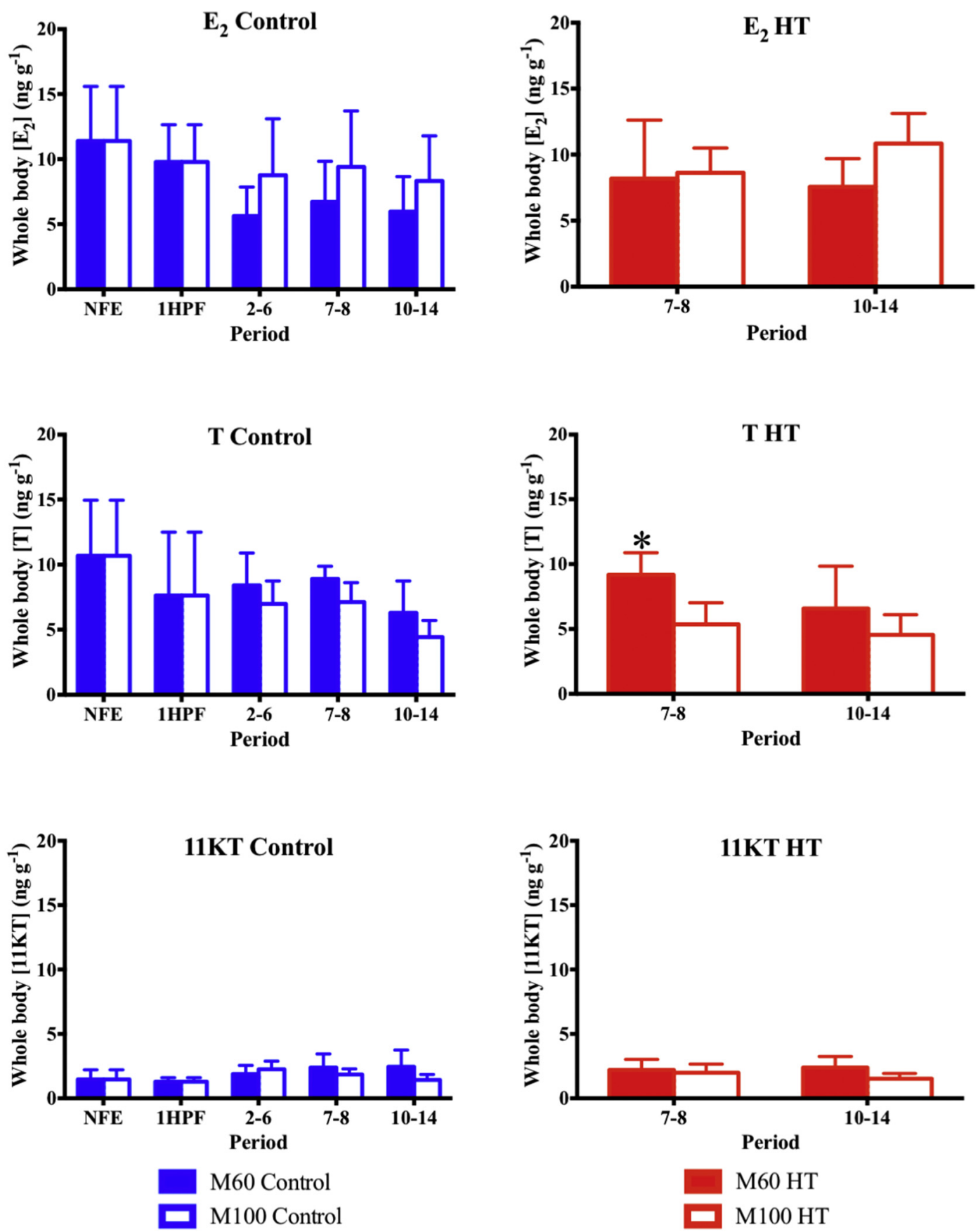

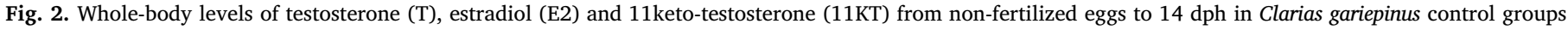

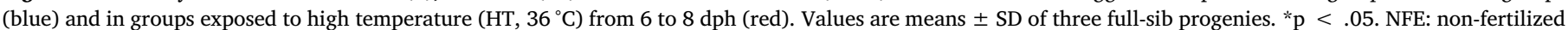

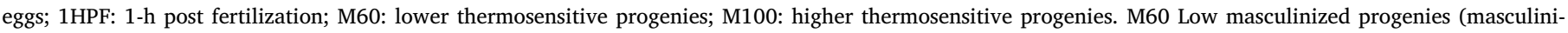

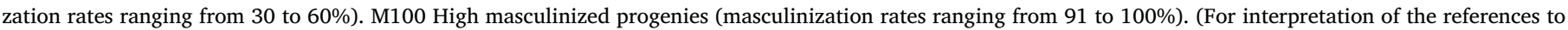
colour in this figure legend, the reader is referred to the web version of this article.)

elevated in HT-promoting male (Diotel et al., 2010). Cyp19a1b gene was either upregulated in undifferentiated Nile tilapia treated with $17 \alpha$-ethynylestradiol (Gennotte et al., 2014) or inhibited in both African catfish juveniles and Pengze crucian carp (Carassius auratus var. Pengze, Pcc) treated with $17 \alpha$-methyltestosterone (Raghuveer et al., 2005; Zheng et al., 2016).

In the present study, no strong relations were found between cyp19a1b relative expression and whole body E2 concentration, neither with sex-ratio of control groups; indicating that brain aromatase did not regulate $\mathrm{E} 2$ concentration during the thermosensitive period in African catfish. In juveniles and adults, E2 synthesis from $\mathrm{T}$ is mainly catalyzed by cyp19a1a (gonadal aromatase) in ovaries. The high expression of cyp19a1b in brain is related to an auto-regulated loop of estrogen and aromatizable androgen through a mechanism that involves estrogen receptors and the estrogen response element located on the cyp19a1b promoter (Diotel et al., 2010; Le Page et al., 2010). Since we did not evaluate cyp19a1a gene expression or aromatase enzyme activity in gonad, sex steroid hormones are synthetized in several organs such as brain, gonads and kidney (Baroiller et al., 1999; Tokarz et al., 2015), it is difficult to interpret measured sex steroid hormones levels in the present study. However, when we divided the larvae into two groups according to the observed masculinization rate (M60 and M100 as 

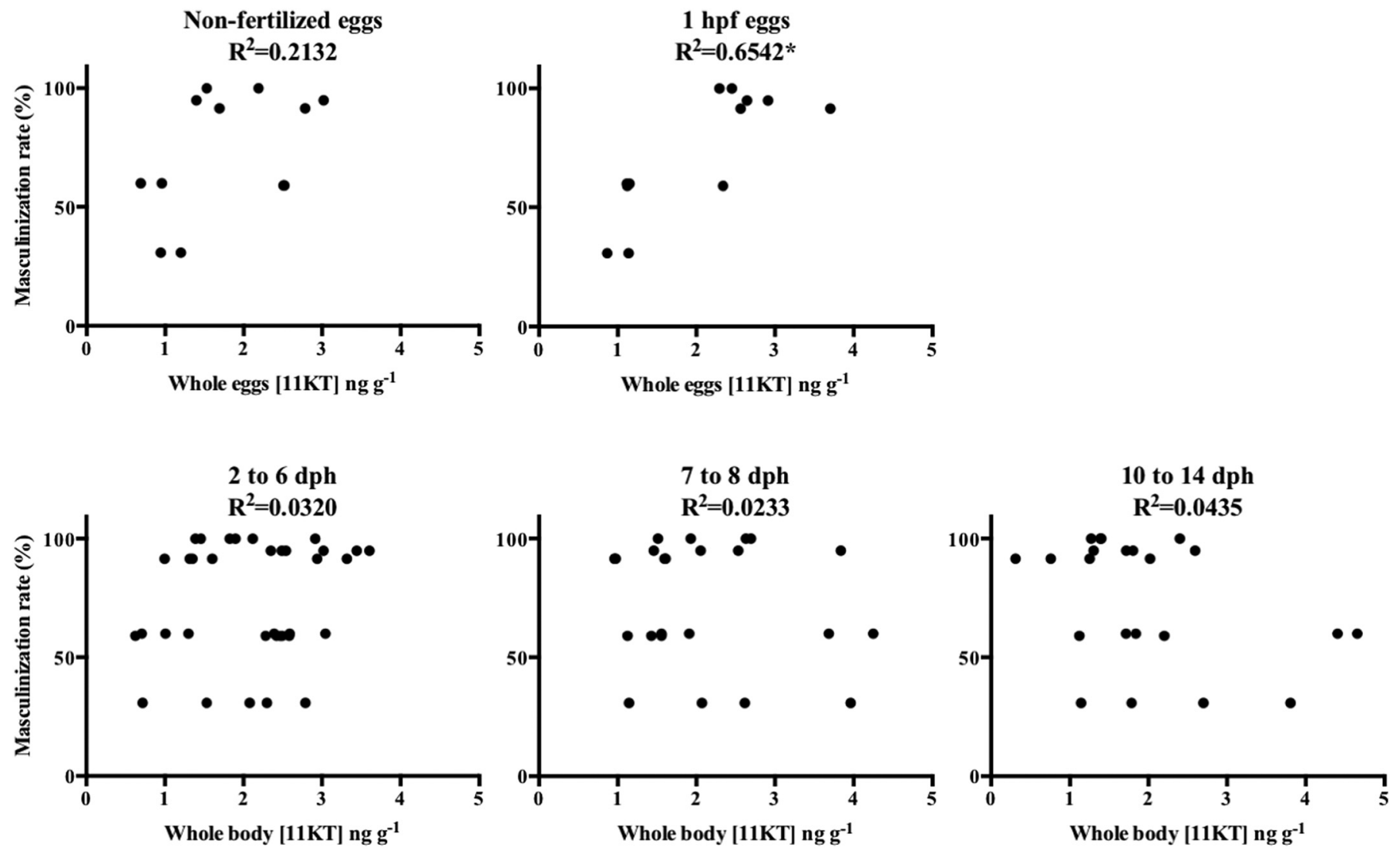

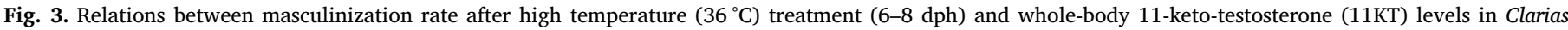
gariepinus. Each point represents duplicated value at each sampling date in the six full-sib progenies. ${ }^{*} \mathrm{p}<.05$.
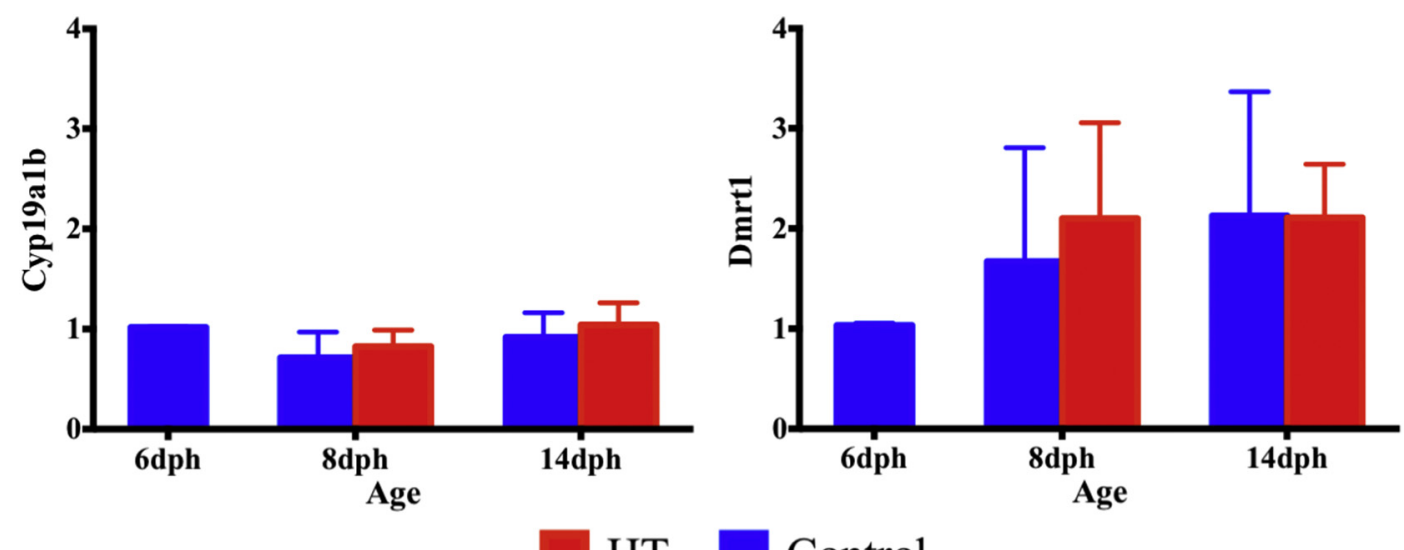

\section{HT Control}

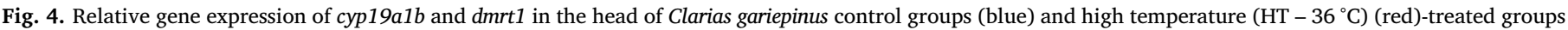

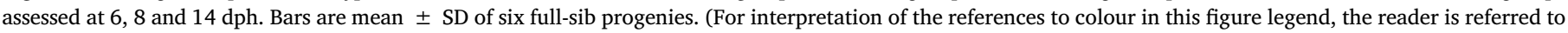
the web version of this article.)

previously described), the group with the lowest masculinization rate displayed a significantly increased expression of cyp19a1b after HT treatment at $14 \mathrm{dph}$. This suggests a potential implication of brain in HT masculinizing process in African catfish.

During the experimental period, no expression of foxl2 was measured in the heads of African catfish. Nevertheless, foxl2 was found to regulate cyp19a1b expression in adult female brain (Sridevi et al., 2012). Our results suggest that the transcriptional regulation of cyp19a1b via foxl2 occurs later.

This study showed that even if masculinization is induced by early exposure to HT (in African catfish), it doesn't affect the levels of whole body sex steroid hormones, nor cyp19a1b neither dmrt1 expressions in the brain before histological gonad differentiation. HT temperature may act on other target (such as primordial germ cells as in others species) to induce masculinization in African catfish. Indeed, in medaka larvae, it was strongly suggested that HT induced masculinization through an elevation of whole body cortisol level, which in turn, caused an inhibition of germ cells proliferation (Hayashi et al., 2010). Similar to zebrafish, HT treatment during sex differentiation caused oocyte apoptosis, which in turn led to sex reversal of genetic females (Uchida et al., 2004). Even if histological observations of gonadal development during HT application (6 to $8 \mathrm{dph}$ ) were not performed in the current 

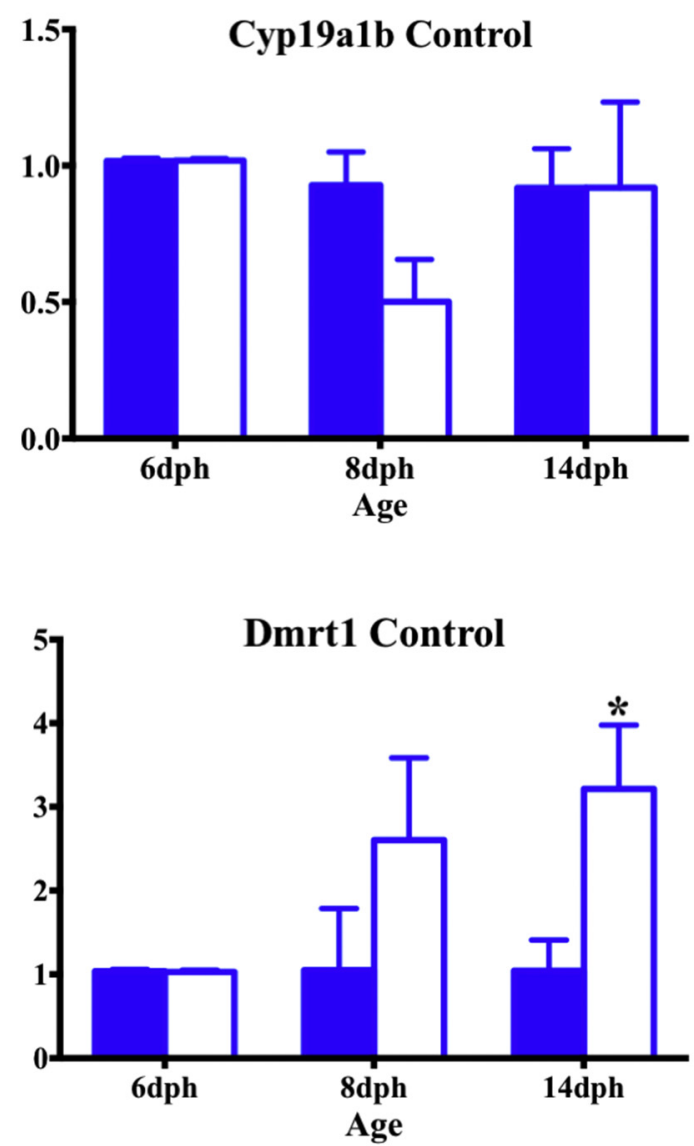

M60 Control

M100 Control

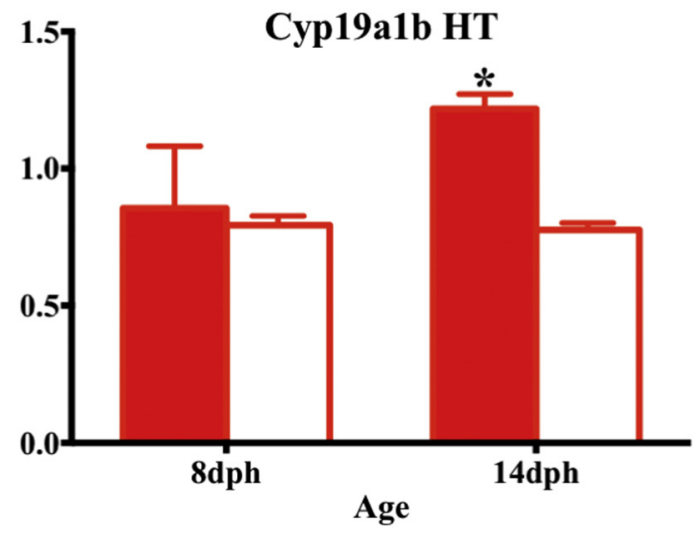

Dmrt1 HT

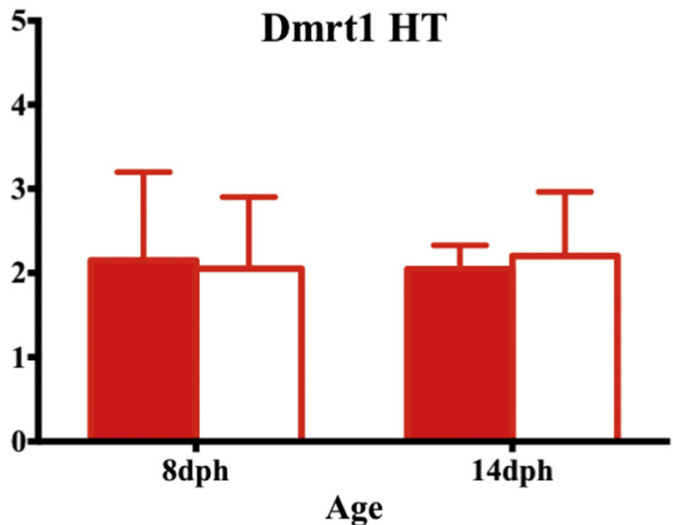

M60 HT

M100 HT

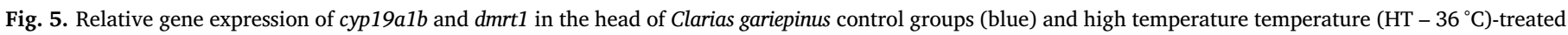

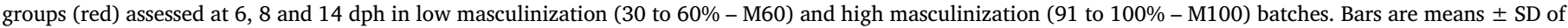
three full-sib progenies. ${ }^{*} \mathrm{p}<.05$. (For interpretation of the references to colour in this figure legend, the reader is referred to the web version of this article.)

study, African catfish showed undifferentiated gonads with somatic and primordial germ cells at $10 \mathrm{dph}$ during normal development (Santi et al., 2016). Thus, we can hypothesize that HT treatment could influence somatic and/or germ cells to induce sex reversal in African catfish. HT could also induce a rise of cortisol concentration, a glucocorticoid stress hormone, during its application to stimulate masculinization. The role of cortisol in temperature induced sex reversal was reviewed in fish (Baroiller and D'Cotta, 2016; Fernandino et al., 2013; Shen and Wang, 2014). Regarding molecular mechanisms, HT could also influence sex differentiation through DNA methylation one of the main epigenetic process involved in fish sex differentiation (Baroiller and D'Cotta, 2016; Piferrer, 2013). Indeed, in the European sea bass and Nile tilapia, exposure to HT increased the methylation of cyp19a promoter in female, which was inversely correlated to gene expression in order to induce masculinization (Navarro-Martín et al., 2011; Wang et al., 2017). Therefore, investigation on the processes cited above or others in African catfish are required to elucidate HT masculinization process.

In summary, we showed that high temperature did not affect neither the levels of main sex steroid hormones (E2, 11KT and T), nor cyp19a1b and dmrt1 relative expressions in the brain, but induced masculinization in African catfish progenies. Sex steroid assays have shown an important transfer from maternal origin of the three steroids that could be used as steroidogenesis in this species. Nevertheless, we demonstrated that progenies with low masculinization display a high relative expression of the cyp19a1b gene after high temperature treatment at 14 $\mathrm{dph}$. Concomitantly, a low relative expression of the $d m r t 1$ gene was observed in these progenies (control group at $14 \mathrm{dph}$ ). These results suggest a potential implication of brain in high temperature masculinizing process in African catfish progenies.

\section{Acknowledgments}

Financial support for this work was provided by ARES-CCD: "Académie de Recherche et d'Enseignement Supérieur" in an Interuniversity targeting program: "Projet PIC Aquaculture ULg/UPB Burkina Faso" between the University of Liege, Belgium and the Polytechnic University of Bobo-Dioulasso, Burkina Faso. S. Santi is a $\mathrm{PhD}$ grant holder from ARES-CCD.

\section{References}

Baroiller, J.-F., D'Cotta, H., 2016. The Reversible sex of Gonochoristic fish: Insights and Consequences. Sex. Dev. 10, 242-266. https://doi.org/10.1159/000452362.

Baroiller, J.F., Guiguen, Y., Fostier, A., 1999. Endocrine and environmental aspects of sex differentiation in fish. Cell. Mol. Life Sci. 55, 910-931.

Baroiller, J.F., D'Cotta, H., Saillant, E., 2009. Environmental effects on fish sex determination and differentiation. Sex. Dev. 3, 118-135. https://doi.org/10.1159/ 000223077 10.1016/j. aquaculture.2009.05.004.

Blazquez, M., Somoza, G.M., 2010. Fish with thermolabile sex determination (TSD) as models to study brain sex differentiation. Gen. Comp. Endocrinol. 166, 470-477. D'Cotta, H., Fostier, A., Guiguen, Y., Govoroun, M., Baroiller, J., 2001a. Search for genes 
involved in the temperature-induced gonadal sex differentiation in the tilapia, Oreochromis niloticus. J. Exp. Zool. 290, 574-585. https://doi.org/10.1002/jez. 1108.

D'Cotta, H., Fostier, A., Guiguen, Y., Govoroun, M., Baroiller, J.F., 2001b. Aromatase plays a key role during normal and temperature-induced sex differentiation of tilapia oreochromis niloticus. Mol. Reprod. Dev. 59, 265-276.

Devlin, R.H., Nagahama, Y., 2002. Sex determination and sex differentiation in fish : an overview of genetic, physiological, and environmental inf luences. Aquaculture 208, 191-364.

Diotel, N., Page, Y.L., Mouriec, K., Tong, S.-K.K., Pellegrini, E., Vaillant, C., Anglade, I. Brion, F., Pakdel, F., Chung, B.C., Kah, O., Le Page, Y., Mouriec, K., Tong, S.-K.K., Pellegrini, E., Vaillant, C., Anglade, I., Brion, F., Pakdel, F., Chung, B.C., Kah, O., 2010. Aromatase in the brain of teleost fish: expression, regulation and putative functions. Front. Neuroendocrinol. 31, 172-192.

Fan, Z., Zou, Y., Jiao, S., Tan, X., Wu, Z., Liang, D., Zhang, P., You, F., 2017. Significant association of cyp19a promoter methylation with environmental factors and gonadal differentiation in olive flounder Paralichthys olivaceus. Comp. Biochem. Physiol. Part A Mol. Integr. Physiol. 208, 70-79. https://doi.org/10.1016/j.cbpa.2017.02.017.

Fernandino, J.I., Hattori, R.S., Moreno Acosta, O.D., Strüssmann, C.A., Somoza, G.M., 2013. Environmental stress-induced testis differentiation: Androgen as a by-product of cortisol inactivation. Gen. Comp. Endocrinol. https://doi.org/10.1016/j.ygcen. 2013.05.024.

Fostier, A., Jalabert, B., 1986. Steroidogenesis in rainbow trout (Salmo gairdneri) at various pre-ovulatory stages: changes in plasma hormone levels and in vivo and in vitro responses of the ovary to salmon gonadotropin. Fish Physiol. Biochem. 2 87-89.

Galbusera, P., Volckaert, F.A.M.M., Ollevier, F., 2000. Gynogenesis in the African catfish Clarias gariepinus (Burchell, 1822) III. Induction of endomitosis and the presence of residual genetic variation. Aquaculture 185, 25-42. https://doi.org/10.1016/S00448486(99)00339-7.

Gennotte, V., Mélard, C., D'Cotta, H., Baroiller, J.F., Rougeot, C., 2014. The sensitive period for male-to-female sex reversal begins at the embryonic stage in the Nile tilapia and is associated with the sexual genotype. Mol. Reprod. Dev. 81, 1146-1158. https://doi.org/10.1002/mrd.22436.

Gennotte, V., Akonkwa, B., Mélard, C., Denoël, M., Cornil, C.A., Rougeot, C., 2017. Do sex reversal procedures differentially affect agonistic behaviours and sex steroid levels depending on the sexual genotype in Nile tilapia? J. Exp. Zool. Part A Ecol. Genet. Physiol. 327. https://doi.org/10.1002/jez.2080.

Guerrero, R.D., Shelton, W.L., 1974. An Aceto-Carmine Squash Method for Sexing Juvenile Fishes. Progress. Fish-Culturist 36, 56. https://doi.org/10.1577/1548 8659(1974)36[56:AASMFS]2.0.CO;2.

Guiguen, Y., Fostier, A., Piferrer, F., Chang, C.F., 2010. Ovarian aromatase and estrogens: a pivotal role for gonadal sex differentiation and sex change in fish. Gen. Comp. Endocrinol. 165, 352-366. https://doi.org/10.1016/j.ygcen.2009.03.002.

Hattori, R.S., Gould, R.J., Fujioka, T., Saito, T., Kurita, J., Strüssmann, C.A., Yokota, M., Watanabe, S., 2007. Temperature-dependent sex determination in Hd-rR Medaka Oryzias latipes: gender sensitivity, thermal threshold, critical period, and DMRT1 expression profile. Sex. Dev. 1, 138-146.

Hattori, R.S., Fernandino, J.I., Kishil, A., Kimura, H., Kinno, T., Oura, M., Somoza, G.M., Yokota, M., Strüssmann, C.A., Watanabe, S., 2009. Cortisol-induced masculinization: Does thermal stress affect gonadal fate in pejerrey, a teleost fish with temperaturedependent sex determination? PLoS One 4https://doi.org/10.1371/journal.pone 0006548. 7 p.

Hayashi, Y., Kobira, H., Yamaguchi, T., Shiraishi, E., Yazawa, T., Hirai, T., Kamei, Y., Kitano, T., 2010. High Temperature Causes Masculinization of Genetically Female Medaka by Elevation of Cortisol. Mol. Reprod. Dev. 77, 679-686.

Heule, C., Salzburger, W., Böhne, A., 2014. Genetics of sexual development: an evolutionary playground for fish. Genetics 196, 579-591. https://doi.org/10.1534/ genetics.114.161158.

Ijiri, S., Kaneko, H., Kobayashi, T., Wang, D.-S., Sakai, F., Paul-Prasanth, B., Nakamura M., Nagahama, Y., 2008. Sexual Dimorphic Expression of Genes in Gonads during early Differentiation of a Teleost fish, the Nile Tilapia Oreochromis niloticus1. Biol. Reprod. 78, 333-341. https://doi.org/10.1095/biolreprod.107.064246.

Kwon, J.Y., McAndrew, B.J., Penman, D.J., 2001. Cloning of brain aromatase gene and expression of brain and ovarian aromatase genes during sexual differentiation in genetic male and female Nile tilapia Oreochromis niloticus. Mol. Reprod. Dev. 59, 359-370. https://doi.org/10.1002/mrd.1042.

Le Page, Y., Diotel, N., Vaillant, C., Pellegrini, E., Anglade, I., Mérot, Y., Kah, O., 2010. Aromatase, brain sexualization and plasticity: the fish paradigm. Eur. J. Neurosci. 32, 2105-2115.

Li, C.G., Wang, H., Chen, H.J., Zhao, Y., Fu, P.S., Ji, X.S., 2014. Differential expression analysis of genes involved in high-temperature induced sex differentiation in Nile tilapia. Comp. Biochem. Physiol. Part B Biochem. Mol. Biol. 177-178, 36-45. https:// doi.org/10.1016/j.cbpb.2014.08.006.

Livak, K.J., Schmittgen, T.D., 2001. Analysis of relative gene expression data using realtime quantitative PCR and the 2- $\Delta \Delta C T$ method. Methods 25, 402-408. https://doi. org/10.1006/meth.2001.1262.

Mandiki, S.N.M., Babiak, I., Bopopi, J.M., Leprieur, F., Kestemont, P., 2005. Effects of sex steroids and their inhibitors on endocrine parameters and gender growth differences in Eurasian perch (Perca fluviatilis) juveniles. Steroids 70, 85-94. https://doi.org/10. 1016/j.steroids.2004.10.009.

Marchand, O., Govoroun, M., D'Cotta, H., McMeel, O., Lareyre, J.-J., Bernot, A., Laudet, V., Guiguen, Y., 2000. DMRT1 expression during gonadal differentiation and spermatogenesis in the rainbow trout, Oncorhynchus mykiss. Biochim. Biophys. Acta Gene Struct. Expr. 1493, 180-187. https://doi.org/10.1016/S0167-4781(00) 00186-X
Mei, J., Gui, J.F., 2015. Genetic basis and biotechnological manipulation of sexual dimorphism and sex determination in fish. Sci. China Life Sci. https://doi.org/10.1007/ s11427-014-4797-9.

Navarro-Martín, L., Viñas, J., Ribas, L., Díaz, N., Gutiérrez, A., Di Croce, L., Piferrer, F., 2011. DNA methylation of the gonadal aromatase (cyp19a) promoter is involved in temperature-dependent sex ratio shifts in the European sea bass. PLoS Genet. 7.

Perrin, N., 2016. Random sex determination: when developmental noise tips the sex balance. BioEssays 38, 1218-1226. https://doi.org/10.1002/bies.201600093.

Piferrer, F., 2013. Epigenetics of sex determination and gonadogenesis. Dev. Dyn. 242, 360-370.

Piferrer, F., Ribas, L., Díaz, N., 2012. Genomic approaches to study genetic and environmental influences on fish sex determination and differentiation. Mar. Biotechnol. 14, 591-604.

Poonlaphdecha, S., Pepey, E., Canonne, M., de Verdal, H., Baroiller, J.F., D'Cotta, H., 2013. Temperature induced-masculinisation in the Nile tilapia causes rapid up-regulation of both dmrt1 and amh expressions. Gen. Comp. Endocrinol. 193, 234-242.

Raghuveer, K., Senthilkumaran, B., 2009. Identification of multiple dmrt1s in catfish: Localization, dimorphic expression pattern, changes during testicular cycle and after methyltestosterone treatment. J. Mol. Endocrinol. 42, 437-448.

Raghuveer, K., Garhwal, R., Wang, D.S., Bogerd, J., Kirubagaran, R., Rasheeda, M.K. Sreenivasulu, G., Bhattachrya, N., Tharangini, S., Nagahama, Y., Senthilkumaran, B., 2005. Effect of methyltestosterone- and ethynyl estradiol-induced sex differentiation on catfish, Clarias gariepinus: expression profiles of DMRT1, Cytochrome P450 aromatases and 3 -hydroxysteroid dehydrogenase. Fish Physiol. Biochem. 31, 143-147.

Raghuveer, K., Senthilkumaran, B., Sudhakumari, C.C., Sridevi, P., Rajakumar, A., Singh, R., Murugananthkumar, R., Majumdar, K.C., 2011. Dimorphic expression of various transcription factor and steroidogenic enzyme genes during gonadal ontogeny in the air-breathing catfish, Clarias gariepinus. Sex. Dev. 5, 213-223.

Rougeot, C., Krim, A., Mandiki, S.N.M., Kestemont, P., Mélard, C., 2007. Sex steroid dynamics during embryogenesis and sexual differentiation in Eurasian perch, Perca fluviatilis. Theriogenology 67, 1046-1052.

Santi, S., Gennotte, V., Toguyeni, A., Mélard, C., Antoine, N., Rougeot, C., 2016. Thermosensitivity of the sex differentiation process in the African catfish, Clarias gariepinus: Determination of the thermosensitive period. Aquaculture 455, 73-80.

Santi, S., Rougeot, C., Toguyeni, A., Gennotte, V., Kebe, I., Melard, C., 2017. Temperature preference and sex differentiation in african catfish, Clarias gariepinus. J. Exp. Zool. Part A Ecol. Genet. Physiol. 327, 28-37. https://doi.org/10.1002/jez.2066.

Selim, K.M., Shinomiya, A., Otake, H., Hamaguchi, S., Sakaizumi, M., 2009. Effects of high temperature on sex differentiation and germ cell population in medaka, Oryzias latipes. Aquaculture 289, 340-349. https://doi.org/10.1016/j.aquaculture.2008.12. 019.

Senthilkumaran, B., Sudhakumari, C.C., Mamta, S.K., Raghuveer, K., Swapna, I., Murugananthkumar, R., 2015. "Brain sex differentiation" in teleosts: emerging concepts with potential biomarkers. Gen. Comp. Endocrinol. 220, 33-40. https://doi. org/10.1016/j.ygcen.2015.06.003.

Shen, Z.-G., Wang, H.-P., 2014. Molecular players involved in temperature-dependent sex determination and sex differentiation in Teleost fish. Genet. Sel. Evol. 46, 26. https:// doi.org/10.1186/1297-9686-46-26.

Socorro, S., Martins, R.S., Deloffre, L., Mylonas, C.C., Canario, A.V.M., 2007. A cDNA for European sea bass (Dicentrachus labrax) 11ß-hydroxylase: Gene expression during the thermosensitive period and gonadogenesis. Gen. Comp. Endocrinol. 150, 164-173. https://doi.org/10.1016/j.ygcen.2006.07.018.

Sridevi, P., Chaitanya, R.K., Dutta-Gupta, A., Senthilkumaran, B., 2012. FTZ-F1 and FOXL2 up-regulate catfish brain aromatase gene transcription by specific binding to the promoter motifs. Biochim. Biophys. Acta Gene Regul. Mech. 1819, 57-66.

Sun, P., You, F., Ma, D., Li, J., Zhang, P., 2013. Sex steroid changes during temperatureinduced gonadal differentiation in Paralichthys olivaceus (Temminck \& Schegel, 1846). J. Appl. Ichthyol. 29, 886-890. https://doi.org/10.1111/jai.12128.

Tchoudakova, A., Callard, G.V., 1998. Identification of multiple CYP19 genes encoding different cytochrome P450 aromatase isozymes in brain and ovary. Endocrinology 139, 2179-2189.

Tokarz, J., Möller, G., Hrabě De Angelis, M., Adamski, J., 2015. Steroids in teleost fishes: a functional point of view. Steroids 103, 123-144. https://doi.org/10.1016/j. steroids.2015.06.011.

Uchida, D., Yamashita, M., Kitano, T., Iguchi, T., 2004. An aromatase inhibitor or high water temperature induce oocyte apoptosis and depletion of P450 aromatase activity in the gonads of genetic female zebrafish during sex-reversal. Comp. Biochem. Physiol. Part A Mol. Integr. Physiol. 137, 11-20. https://doi.org/10.1016/S1095 6433(03)00178-8.

Vizziano-Cantonnet, D., Anglade, I., Pellegrini, E., Gueguen, M.-M., Fostier, A., Guiguen, Y., Kah, O., 2011. Sexual dimorphism in the brain aromatase expression and activity, and in the central expression of other steroidogenic enzymes during the period of sex differentiation in monosex rainbow trout populations. Gen. Comp. Endocrinol. 170, 346-355. https://doi.org/10.1016/j.ygcen.2010.10.009.

Wang, Y.Y., Sun, L.X., Zhu, J.J., Zhao, Y., Wang, H., Liu, H.J., Ji, X.S., 2017. Epigenetic control of cyp19a1a expression is critical for high temperature induced Nile tilapia masculinization. J. Therm. Biol. 69, 76-84. https://doi.org/10.1016/j.jtherbio.2017. 06.006.

Webster, K.A., Schach, U., Ordaz, A., Steinfeld, J.S., Draper, B.W., Siegfried, K.R., 2017. Dmrt1 is necessary for male sexual development in zebrafish. Dev. Biol. 422, 33-46. https://doi.org/10.1016/j.ydbio.2016.12.008.

Zheng, Y., Chen, J., Liu, Y., Gao, J., Yang, Y., Zhang, Y., Bing, X., Gao, Z., Liang, H., Wang, Z., 2016. Molecular mechanism of endocrine system impairment by $17 \alpha$-methyltestosterone in gynogenic Pengze crucian carp offspring. Ecotoxicol. Environ. Saf. 128, 143-152. https://doi.org/10.1016/j.ecoenv.2015.11.034. 